\title{
EXPERIÊNCIA, ATIVIDADE, CORPO: REFLEXÕES NA CONFLUÊNCIA DA PSICOSSOCIOLOGIA DO TRABALHO E ERGOLOGIA
}

EXPERIENCE, ACTIVITY, BODY: REFLECTIONS ON THE CONFLUENCE OF PSYCHOSOCIOLOGY OF WORK AND ERGOLOGY

\author{
EXPERIENCIA, ACTIVIDAD, CUERPO: REFLEXIONES EN LA CONFLUENCIA DE LA \\ PSICOSOCIOLOGÍA DEL TRABAJO Y ERGOLOGÍA
}

\author{
Carolina Couto da Mata* \\ Fabiana Goulart de Oliveira ${ }^{* *}$ \\ Vanessa Andrade Barros ${ }^{* *}$
}

\begin{abstract}
RESUMO
A experiência, assim como os processos de subjetivação que decorrem das transformações do sujeito por meio da atividade, evidenciam-se na produção de novos saberes, na aquisição de habilidades, no desenvolvimento de competências. O corpo é a base dessas transformações. Ele sustenta o conjunto de elementos que se apresentam no debate de normas e valores que caracterizam a atividade. Esta se produz num sistema de interações entre indivíduo e ambiente, em que as estruturas internas dos atores envolvidos se determinaram. Nosso objetivo neste artigo é refletir sobre os processos constitutivos de experiências que têm no corpo, na atividade e na dinâmica saúde-doença seus elementos norteadores.
\end{abstract}

Palavras-chaves: Experiência. Atividade. Corpo. Psicossociologia do trabalho. Ergologia.

\begin{abstract}
The experience, as well as the processes of subjectivation that result from the transformations of the subject through the activity, are evidenced in the
\end{abstract}

\footnotetext{
* Graduada em Terapia Ocupacional, mestre e doutora em Psicologia pela UFMG. Professora adjunta do Dep. de Terapia Ocupacional da Universidade Federal da Paraíba (UFPB). Desenvolve pesquisas sobre uso abusivo de álcool e outras drogas e açôes de prevenção, tratamento, reabilitação e políticas públicas em AD. E-mail: carolcoutomata@gmail.com

** Graduada em psicologia, mestre em Engenharia de produção pela UFMG e doutora em Psicologia Social pela mesma universidade com bolsa de doutorado Sanduíche no CNAM, em Paris. Pesquisadora do Laboratório de Estudos sobre Trabalho, Cárcere e Direitos Humanos/UFMG e do Núcleo Alternativas de Produção em Economia Solidária da Escola de Engenharia da UFMG. E-mail: fabiana.goulart@yahoo.com.br

***Graduada em Psicologia, mestre em Administração e doutora em Sociologia pela Université de Paris 7 com pós doutorado noCNAM/Paris. Professora associada do dept. de Psicologia da Universidade Federal de Minas Gerais (UFMG). Coordena o Laboratório de Estudos sobre Trabalho, Cárcere e Direitos Humanos. É membro fundador do Instituto DH: promoção, pesquisa e intervenção em direitos Humanos e Cidadania. E-mail: vanessa.abarros@gmail.com
} 
production of new knowledge, in the acquisition of skills, in the development of competences. The body is the basis of these transformations. It supports the set of elements that present themselves in the debate of norms and values that characterize the activity. This occurs in a system of interactions between individual and environment, in which the internal structures of the actors involved are coterminous. Our objective in this article is to reflect on the constitutive processes of experiences that have their guiding elements in the body, in the activity and in the health-disease dynamics.

Keywords: Experience. Activity. Body. Psychosociology of work. Ergology.

\section{RESUMEN}

La experiencia, así como los procesos de subjetivación que se derivan de las transformaciones del sujeto por medio de la actividad, evidencianse en la producción de nuevos saberes, en la adquisición de habilidades, en el desarrollo de competencias. El cuerpo es la base de esas transformaciones. Sustentase el conjunto de elementos que se presentan en el debate de normas y valores que caracterizan la actividad. Esta se produce en un sistema de interacciones entre individuo y ambiente, en que las estructuras internas de los actores involucrados codeterminanse. Nuestro objetivo en este artículo es reflexionar sobre los procesos constitutivos de experiencias que tienen sus elementos orientadores en el cuerpo, en la actividad y en la dinámica saludenfermedad.

Palabras clave: Experiencia. Actividad. Cuerpo. Psicosociología del trabajo. Ergonomía.

\section{INTRODUÇÃO}

A Psicossociologia do Trabalho, ao discutir o desenvolvimento da atividade $\triangle$ própria do sujeito e ao mesmo tempo o processo de subjetivação que daí Idecorre, considera a relação existente entre a atividade e a práxis, bem como sua participação no trabalho de cultura e em todos os campos da atividade (Lhuilier, 2014, p.17). Constitui-se assim em um importante aporte teórico para o entendimento de aspectos subjetivos, simbólicos, pulsionais e libidinais envolvidos nas vivências de prazer e sofrimento nas atividades dos homens e mulheres no trabalho e em suas repercussóes cotidianas, colocando em cena o sujeito e sua experiência, em suas complexas maneiras de viver a vida.

Para tanto, dialoga com diferentes campos disciplinares, buscando a inter, multi e transdisciplinaridade na produção de saberes. De certa forma, ela se aproxima da perspectiva ergológica de análise da atividade (Schwartz, 2007), pois também trata de sujeitos inteiros, imersos em sua experiência antropológica, 
contribuindo para esclarecer como, ao serem confrontados com o real, gerem diversos aspectos - históricos, sociais, técnicos, singulares - que perpassam sua atividade em um constante e permanente debate de normas e valores (Schwartz, 2007).

$\mathrm{Na}$ confluência desses dois campos - Psicossociologia do Trabalho e Ergologia - a experiência se apresenta como um valioso conceito para o entendimento dos sujeitos em suas atividades, como discutiremos a seguir.

\section{EXPERIÊNCIA}

A experiência diz respeito àquilo que afeta o sujeito e ao modo como ele atribui ou não um sentido àquilo que nele acontece. Isso ocorre no envolvimento com a vida, consigo mesmo, com os outros, com o mundo, com o pensamento, com a linguagem, com o trabalho e também com aquilo que esse sujeito deixa de dizer, pensar e fazer (Larrosa, 2015). Implica, assim, em sua abertura ao mundo e à capacidade de ser por ele afetado. O sujeito da experiência pode ser definido por sua abertura, receptividade e disponibilidade para o que lhe acontece e o transforma, pois aquilo de que ele faz experiência, dele se apodera, afirma Larrosa (2015).

É no enfrentamento cotidiano do mundo que a experiência se produz, por meio da atividade, através da qual o sujeito se expõe, se coloca à prova, se submete aos medos, às frustrações, e aos limites. A travessia desses enfrentamentos permite o desenvolvimento da experiência e a produção de um saber e de uma práxis. Nesse aspecto, a experiência pode ser compreendida como aprendizagem que decorre do encontro - e muitas vezes do confronto - do sujeito com o real.

Dizemos que um sujeito "adquiriu experiência" quando ele aprende, desenvolve competências, se socializa num determinado grupo ou situação ou torna-se hábil para agir "à sua maneira singular", orientado por normas e valores de um dado contexto. Neste sentido, a formação de um sujeito é o resultado de suas experiências e socializações no enfrentamento das dificuldades encontradas em uma determinada prática social.

Enquanto aprendizagem, a experiência é um patrimônio vivido, individual, produtor de uma identidade e, ao mesmo tempo, coletivo, que se transmite de uma geração a outra, assumindo um papel fundamental na produção humana (Benjamim, 2012). Expressa um tipo de amálgama entre o homem, o seu meio social e a sua cultura, numa síntese singular entre heranças, tradições e condiçôes sociais (Thompson, 1987). Ela se produz e se renova continuamente por meio do trabalho e da vida social e sua transmissão vincula o sujeito ao seu patrimônio cultural, por isso é fonte de sentido (Kehl, 2009). 
Cada sujeito experimenta suas situações singulares em conexão com as relações produtivas - determinadas como necessidades, interesses ou antagonismos - das mais complexas maneiras e assim as trata em sua consciência e na sua cultura, ao agir no mundo. Nesse sentido, a experiência se liga à atividade, influenciando seu percurso e sendo por ela influenciada. Por meio da atividade, a experiência produz saberes que, por sua vez, produzem novas experiências.

\section{EXPERIÊNCIA E ATIVIDADE}

A separação entre corpo e mente, assim como entre teoria e prática, é típica da visão cartesiana que marca os modelos tayloristas e que separa também concepção e ação, conhecimento e habilidades. Vários estudos no entanto (Lave, 1988; Lave \& Wenger, 1991) demonstram a superação dessas dualidades, afirmando que o saber é produto de uma unidade entre cognição e engajamento corporal, dentro de um contexto social. Essa visão lança luz sobre a aprendizagem prática e corrobora a ideia de que o saber se produz na experiência, por meio da atividade.

A atividade é sinônimo de ação (Lhuilier $e t a l, 2013)$ e está associada à práxis. Ela se produz num sistema de interações entre indivíduo e ambiente, em que as estruturas internas dos atores envolvidos - sua constituição fisiológica, sua personalidade, sua competência, sua história no trabalho e fora dele, e nas estruturas do ambiente, incluído o social, se codeterminam (Theureau, 2015). Dessa forma, a produção de um saber ou de uma experiência é também um processo subjetivo que envolve a produção de uma identidade.

A experiência fundamenta o sentimento de identidade. Ela passa inevitavelmente pela atividade, que faz a conexão entre o sujeito e o coletivo ou social. É na atividade e pela atividade que o coletivo se constitui em cada sujeito e organiza o seu contato com o real (Clot, 2010). No encontro com o real, o sujeito se coloca à prova, confronta suas ideias, seu fazer, seus processos identitários. Esse confronto convoca o sujeito a produzir sentido, a realizar experiências e, dessa forma, a criar condições para o processo de transformação e de enfrentamento da vida.

A abordagem da "aprendizagem situada", proposta por Lave e Wenger (1991), sugere que a aprendizagem de uma prática depende do engajamento do sujeito em determinada comunidade. Segundo os autores, a transformação de um membro novato em experiente, numa determinada comunidade de prática, depende da aquisição de habilidades relativas àquela prática. O novato inicia seu aprendizado a partir de uma participação legitima periférica (Lave \& Wenger, 1991) nas atividades relativas ao grupo de profissionais. Aos poucos, na medida em que tem acesso às atividades do grupo, ele se desloca em direção a uma 
participação plena e assim se forma como um "membro" da "comunidade de prática", da qual está participando. Aqui, o foco da aprendizagem não está na relação mestre-aprendiz, mas na participação na comunidade. Tornar-se experiente em determinada prática requer um conjunto de habilidades que não se restringe a um saber intelectual. Como aponta como Anzieu (citado em Lhuilier, 2016) as habilidades adquiridas no processo de "tornar-se experiente" são incorporadas e, por isso, nunca completamente explicitáveis.

\section{A EXPERIÊNCIA E O CORPO}

A perspectiva ergológica apresenta o corpo como "suporte de polarização valorativa" (Schwartz, 2016), ou seja, por meio dele são produzidos os elementos que configuram os debates de normas e valores que antecedem cada ação, cada escolha que fazemos. Esses debates constituem as dramáticas do uso de si (Schwartz, 2016), que se justificam pela impossibilidade de previsão e racionalização total do mundo.

Essa dimensão dramática é mais evidente nas atividades de trabalho, nas quais critérios de produtividade e eficiência são definidos. No entanto, toda atividade humana envolve uma dramática, cujos debates dão origem a escolhas e renormalizações, que evocam uma dimensão singular do sujeito e propiciam o desenvolvimento da criatividade.

Cada sujeito interpreta e "aplica" as normas a partir de um conjunto de elementos que são influenciados pela sua história singular, sua experiência, sua visão de mundo, pelo contexto específico em que a situação se desenvolve. Tais elementos se apresentam no corpo, que registra a história de cada experiência ou desses microdebates. Trata-se de um corpo-si, (Schwartz \& Derrive, 2007) corpo físico, afetado pela experiência de trabalho ao qual são incorporados o social, o psíquico, o institucional, as normas e valores, e as relações com outros sujeitos e com os produtos dessa experiência.

A experiência de trabalho envolve a produção de um saber que transforma o sujeito, e o constitui como trabalhador, conformando o seu corpo, sua percepção, suas normas e valores, sua relação com o mundo.

A relação do corpo com a tarefa permite o desenvolvimento de uma história singular e com ela, a competência. É no corpo de um trabalhador que a história da atividade se registra. Ele memoriza, organiza, hierarquiza saberes, gestos e procedimentos que são reatualizados no momento oportuno. Como explica Dejours (2012, p. 27), é no "diálogo" com a máquina, (e poderíamos acrescentar, com o objeto de trabalho) onde o trabalhador empresta a ela uma vida, como se ela 
fosse um animal domesticável, que ele desenvolve uma habilidade, uma sensibilidade ou um 'sexto sentido'. E é também com o corpo que ele gere a fadiga ao longo de uma jornada de trabalho, por meio de uma "composição" que cada trabalhador faz com seus históricos, considerando seus pontos fortes e suas fraquezas. (Schwartz, 2014).

Tomemos como exemplo os catadores de materiais recicláveis, que atuam na coleta e separação dos materiais (Oliveira, 2016). Sua experiência prática se apresenta como determinante para o funcionamento e a produtividade do trabalho, nas cooperativas de reciclagem. Ela é que permite o desenvolvimento de habilidades e modos operatórios necessários para responder às exigências da atividade, como identificar, por meio do olfato, características específicas de cada lote de materiais, antecipando procedimentos necessários à sua preservação e à prevenção de acidentes; ou reconhecer diferenças de materiais, como plásticos, através do tato ou do "barulho" que cada um faz, ao ser amassado; ou desenvolver um tipo de movimento do corpo - 'mexer o corpo', que permite ao trabalhador acessar adequadamente quase tudo o que passa pela esteira.

A experiência desenvolvida no trabalho dos catadores produz um tipo de identidade que é expressa na nomeação "catador de materiais recicláveis". Esse nome carrega a história e as regras do ofício, com uma visão de mundo e um projeto de sociedade que os diferencia de outras terminologias como "catador de lixo", "reciclador", "agente ambiental". As transformaçôes corporais nesses trabalhadores incidem, por exemplo, na sua percepção do mundo, a partir do que eles nomeiam como "vício da reciclagem". Na medida em que "se tornam catadores de materiais recicláveis", não conseguem mais deixar de "aproveitar" os materiais que encontram descartados como lixo. Seu trabalho atribui aos resíduos novas classificações, novos lugares - não são mais lixo! - e assim, não provocam mais os mesmos sentimentos como o nojo, a repugnância, o medo, que provocavam no início do trabalho, quando eram ainda novatos na profissão. (Oliveira, 2016; Douglas, 2010)

\section{O CORPO NA EXPERIÊNCIA DE SAÚDE E DE DOENÇA}

Por sua dimensão constitutiva, expressiva e material, por sua natureza física e biológica, o corpo presentifica o ser humano no mundo (Vaz, 1991). É ele que também realiza as intencionalidades humanas. Esse corpo próprio, como é denominado pela Antropologia Filosófica, essa totalidade intencional, ou seja, o Eu corporal, fruto da autoexpressão do sujeito, marca sua presença intencional e ativa no mundo. Vaz (1991) nos ensina que esse sujeito corporal-psicológicosocial-cultural se constitui na relação e articulação do corpo com cada uma dessas 
dimensões. Daí deriva sua imagem corporal, a postura, o ritmo; na articulação com a psique: sua afetividade, sua sexualidade, seu sentimento, sua emoção; com o social: sua comunicação, sua linguagem e o gesto, a expressividade, os símbolos, os comportamento; com a cultura: as tradiçôes culturais de modelagem do corpo (como a ginástica), as condutas que se exprimem por meio do corpo (como o jogo, a refeição, a moda, a etiqueta, o rito, etc.). Essas articulações do sujeito, que com seu corpo próprio ultrapassa sua natureza física e biológica para tornarse sujeito em outras dimensões - psicológica, social e cultural - são a matériaprima para a autocompreensão humana. $\mathrm{O}$ corpo exterioriza a humanidade do sujeito pelas formas expressivas que estrutura, as quais são utilizadas como sinais na relação intersubjetiva com outros sujeitos e como suporte para o processo de significação da sua relação direta e objetiva com o mundo. Nas palavras de Vaz (1991, p. 181), "o corpo é o sujeito, no sentido de constitutivo de sua humanidade". Ele traz um saber fruto da experiência natural e espontânea que se faz da vida (Jorge, 1995). Por tudo isso, tomando como exemplo a experiência da doença, podemos afirmar que o ser humano encontra-se afetado no corpo e em sua condição de sujeito.

Quando o sujeito sente no corpo sua condição de vida limitada por condiçóes exteriores (ambiente, condições de trabalho, precariedade material) ou mesmo pelo abuso continuado de substâncias, caracterizando uma dependência química, por exemplo, ele passa a conferir outro sentido para o que lhe acontece.

$\mathrm{Na}$ dependência química, afetado e impactado pela experiência do limite, marcado no esgotamento da capacidade do corpo, ele se defronta com um real que o questiona, que o angustia, que o faz pensar e dar sentido ao que o afeta (Mata, 2016). É como se o abuso continuado de substâncias, de certa forma, desarticulasse a sua atividade da sua práxis, reduzindo seus gestos e programando suas condutas, debilitando-o e anestesiando sua vida psíquica (Lhuilier, 2016). Esta desarticulação comprometeria a realização da experiência, uma vez que o sujeito deixaria de afetar-se pelo encontro com o real. Aqui, temse uma experiência "enjaulada" por uma lógica, por saberes e práticas que já não respondem mais às necessidades do sujeito (Larrosa, 2015)

Em muitos casos, o corpo passa a ser, para o sujeito, um alarme que chama a atenção para um problema que se experimenta e que pode precipitar a tomada de consciência do que o afeta (Pharo, 2011). A experiência do limite marca um acontecimento, ao longo de uma sucessão de fatos que têm um impacto significativo, a ponto de alterar a trajetória desses sujeitos (Mata, 2016).

Geralmente, é somente a insuficiência desse corpo real, palpável, visível, concreto, que mobiliza o sujeito (Pharo, 2011). São frequentes os sujeitos 
que buscam por auxílio, somente quando o corpo físico demonstra algum comprometimento significativo, mesmo diante das evidências de um grave problema em curso, como quem se envolve no tratamento do tabagismo somente quando um câncer de pulmão já foi diagnosticado. É como se o corpo físico fosse, para esses sujeitos, a única maneira concreta de denunciar um comprometimento de saúde dessa natureza e o fator capaz de mobilizar esse sujeito, no enfrentamento da situação, a algum tipo de reação ao que lhe ocorre: meu pulmão não aguentava mais [puxar o crack], [...] tomei duas caixas de Rivotril e fui parar no pronto socorro - conforme afirmaram alguns dependentes químicos graves ao identificarem situações que marcaram um outro percurso em suas trajetórias de vida (Mata, 2016). Em certo momento, quando eles se deixam afetar pelo que lhes acontece, em vez de aumentar sua performance, de anunciar sua potência e sua capacidade de suportar os efeitos que desejam sentir pelo uso das substâncias psicoativas, esses mesmos corpos revelam aos sujeitos sua fragilidade, sua impotência, seu limite.

A afirmação da impotência do sujeito enuncia uma patologia, no sentido de um sofrimento concreto, uma impossibilidade de a vida acontecer por um impedimento (Canguilhem, 2012). Trata-se de uma incapacidade básica: um corpo que não funciona. Esse limite físico evidencia ao sujeito a finitude da vida e o risco de morte, ou seja, o processo de vulnerabilização do corpo biológico, ao qual ele está se submetendo e sendo submetido, e a experiência do seu tempo limitado ou a impossibilidade de se durar para sempre (Sant'Anna, 2011)

O próprio sujeito seria o responsável pela distinção do ponto em que começa a doença, tendo a si mesmo como a própria referência. "O patológico só começa quando é reconhecido como tal pela consciência marcada pela experiência da doença”" (Safatle, 2011, p.19).

Nesse sentido, não há fenômeno patológico em si. Ele só poderia ser apreciado numa relação: o que é normal numa situação poderia se tornar patológico noutra, dependendo da reação do sujeito e dos instrumentos de ação disponíveis no seu contexto de vida. Um fato seria "normal ou patológico no interior de uma relação entre o organismo e o meio ambiente" (Safatle, 2011, p. 18). O nível de saúde poderia ser avaliado pela capacidade de suportabilidade às mudanças e infidelidades do meio, assim como de enfrentamento das crises e de operar ajustes normativos: "Estar com boa saúde é poder cair doente e poder se recuperar" (Canguilhem, 2012, p.140).

Por outro lado, o impeditivo, em alguns aspectos, pode se tornar uma possibilidade (Viana, 1993). A doença é o que faz o corpo falar e que provoca o pensar. A experiência da doença rompe uma certa imanência silenciosa entre 
o sujeito e o seu próprio corpo e determina exigências de saber que configuram necessidades de cuidado e intervenção. (Safatle, 2011).

Por tudo isso, a doença acabaria revelando uma inovação positiva do sujeito ao instaurar um processo de redimensionamento da vida, quando se é capaz de afastar da doença, pela flexibilidade e criatividade de transformar as normas, como nos ensina Canguilhem (2012). Essa maleabilidade não caracterizaria, no entanto, uma plasticidade instantânea e absoluta, mas uma flexibilidade das normas interpretadas pelo sujeito como habituais, um dinamismo dos modos de ser da vida, dentro de certos limites (Moreira, 2013). Nesse sentido, a saúde e a doença estão relacionadas à capacidade do sujeito de reagir diante das situações que ameaçam a vida (Canguilhem, 2012).

A experiência da doença, seu caráter corporal, orgânico e psíquico, institui um processo de reflexividade, suscita uma angústia e marca a consciência do sujeito ao perceber-se em sofrimento, afetado no corpo e limitado na sua condição de sujeito, ao experimentar sua extensão e suas repercussões em sua trajetória de vida.

A experiência do limite do corpo e suas repercussões em diferentes dimensões da vida, resulta em um saber particular, singular, pessoal e subjetivo - o saber da experiência. Um saber que só tem sentido no modo como constitui o sujeito, sua personalidade, seu caráter, sua ética - modo de conduzir-se - e sua estética - seu estilo. Trata-se de um saber encarnado no sujeito da experiência, que revela sua forma humana singular de estar no mundo, sua existência. Ele deriva da capacidade humana de saber de si de diferentes formas, que ultrapassam a experiência natural e científica e alcançam uma compreensão filosófica (Jorge, 1995): mais do que um saber sobre o sujeito, um saber do sujeito, no seu processo de autoconstituir-se como sujeito.

\section{CONSIDERAÇÕES FINAIS}

A riqueza da experiência se deve à complexa relação entre o sujeito (corpo-si) e o seu coletivo. Como patrimônio vivido, a experiência se constitui enquanto aprendizagem de um modo singular e social de conduzir-se na vida.

Inscrita no corpo, a experiência o transforma, direciona seus gestos e sua conduta, evidencia suas fragilidades e, ao mesmo tempo, permite o desenvolvimento de habilidades e competências, ao responder às exigências do viver, do trabalho e da cultura. Ela se projeta, ainda, para seu exterior, na construção social, em permanentes processos de debates de normas e valores e de renormalizações, constitutivos da atividade humana. 
A experiência envolve a produção de saberes que transformam o sujeito: ao reenviá-lo à singularidade das situações jamais antecipáveis; ao constituí-lo como trabalhador; ao capacitá-lo para enfrentar as situações que ameaçam sua vida e ao convocá-lo a saber de si, do seu corpo, da sua história, da sua cultura e da sua humanidade. 


\section{REFERÊNCIAS}

Benjamim, W. (2012). Magia e técnica, arte e politica: ensaio sobre literatura e história da cultura. São Paulo: Brasiliense. (Obras Escolhidas, v. 1).

Canguilhem, G. (2009). O normal e o patológico. 6a ed. Rio de Janeiro: Forense Universitária.

Canguilhem, G. (2012). O normal e o patológico (7a ed.) (M. T. R. Barrocas Trad). Rio de Janeiro: Forense Universitária.

Clot, Y. (2010). Trabalho e poder de agir. Belo Horizonte: Fabrefactum.

Cunha, C.M., Santos, G.M.A. \& Cunha, D.M. (2015). Quando o trabalho faz pensar (e compartilhar) a experiência do tempo de agora. In F.P.A., Lima, L. B. C. Rabelo, \& M. G. L. Castro (Orgs.). Conectando saberes: dispositivos sociais de prevenção de acidentes e doenças no trabalho. Belo Horizonte. Fabrefactum.

Dejours, C. (2012). Trabalho vivo: trabalho e emancipação. Brasília: Paralelo 15.

Douglas, M. (2010). Pureza e perigo. São Paulo: Perspectiva

Gomes Junior, A.B. \& Cunha, D.M. (2015). Ergologia: um projeto-herança de clínicas singulares. In F.P.A., Lima, L. B. C. Rabelo, \& M. G. L. Castro (Orgs.). Conectando saberes: dispositivos sociais de prevenção de acidentes e doenças no trabalho. Belo Horizonte. Fabrefactum.

Jorge, R. C. (1995). Psicoterapia ocupacional. Belo Horizonte: GESTO.

Kehl, M. R. (2009). Temporalidade e experiência. In M. R. Kehl. O tempo e o cão: a atualidade das depressóes. São Paulo: Boitempo Editorial.

Lave, J. \& Wenger, E. (1991). Situated learning legitimate peripheral participation. Cambridge: Cambridge University Press.

Lave, J (1988). Cognition in Practice: mind, mathematics, and culture in everyday life. Cambridge: Cambridge University Press.

Larrosa, J. B. (2002). Notas sobre a experiência e o saber de experiência. Revista Brasileira de Educação, 19, 9-28.

Larrosa, J. (2015). Tremores: escritos sobre experiência. (C. Antunes, J. W. \& Geraldi, Trad.). Belo Horizonte: Autêntica. 
Lhuilier, D.; Barros, V.A.; Araujo, J. N. G. (2013). Nouvelle revue de psychosociologie, $\mathrm{n}^{\circ}$ 15, Dossier: La psychosociologie du travail: perspectives internationales.

Lhuilier, D. (2014). Introdução à psicossociologia do trabalho. Caderno de Psicologia Social do Trabalho, 17(1) Recuperado a partir de http://www.revistas. usp.br/cpst/article/view/80628/84317

Lhuilier, D. (2016). L'activité, dans et au-delà du monde du travail. In M. A. Dujarier et al. (Orgs), L'activité en théories. Regards croisés sur le travail. (pp. 131-158). Toulouse : Octares.

Mata, C. C. (2016). Outra história: a experiência de dependentes quimicos no enfrentamento da vida. (Tese de Doutorado), Universidade Federal de Minas Gerais, Programa de Pós-Graduação em Psicologia, Belo Horizonte.

Moreira, A. B. (2013). Clínica e resistência: a medicina filosófica de Georges Canguilhem. (Tese de Doutorado). Faculdade de Filosofia, Letras e Ciências Humanas da Universidade de São Paulo, São Paulo.

Oliveira, F. G. (2016). Do "trabalho sujo" à bela obra: o que é triar materiais recicláveis?: um estudo em psicossociologia do trabalho. (Tese de Doutorado). Universidade Federal de Minas Gerais, Programa de Pós-Graduação em Psicologia, Belo Horizonte.

Pharo, P. (2011). Philosophie pratique de la drogue. Paris: Ed. CERF.

Safatle, V. (2011). O que é uma normatividade vital? Saúde e doença a partir de George Canguilhem. Scientiae Studia, 9(1), 11-27.

Sant'Anna, D. B. (2011). Corpos de passagem: ensaios sobre a subjetividade contemporânea. São Paulo: Estação Liberdade.

Schwartz, Y. \&. Durrive, L. (2007). Trabalho e ergologia: conversas sobre a atividade humana. Niterói: Universidade Federal Fluminense.

Schwartz, Y. (2007). Un bref aperçu de l'histoire culturelle du concept d'activité. Activités revue électronique, 4(2), 122 -133.

Schwartz, Y. (2016) Manifesto por um ergoengajamento. In Y. Schwartz \& L. Durrive (Orgs.), Trabalho e ergologia II: diálogos sobre a atividade humana. Belo Horizonte: Fabrefactum. 
Schwartz, Y. (2014). Motivaçôes do conceito de corpo-si: corpo-si, atividade, experiência. Letras de Hoje, 49(3), 259-274.

Theureau, J. (2015). A hipótese da cognição (ou ação) situada e a tradição da análise do trabalho da ergonomia de língua francesa. In F.P.A., Lima, L. B. C. Rabelo, \& M. G. L. Castro (Orgs.). Conectando saberes: dispositivos sociais de prevenção de acidentes e doenças no trabalho. (pp. 285-313). Belo Horizonte. Fabrefactum.

Thompson, E. (1987) A formação da classe operária inglesa. Rio de Janeiro: Paz e Terra.

Vaz, H. C. L. (1991). Antropologia filosófica I. São Paulo: Loyola. (Coleção filosofia 15).

Viana, R. G. V. (1993). Ser ou não ser: educação preventiva do uso de drogas. São Paulo: Loyola. 